\title{
Research on Optimization Energy Management Strategies Based on Driving Cycle Recognition for Plug-in Hybrid Electric Vehicle
}

\author{
Ren Yong ${ }^{a}$, Yang Guanlong ${ }^{b}$, Liang Wei , Liu jie, Tian Xueyong \\ Chongqing Changan New Energy Automobile Co. Ltd, Chongqing, 401120, China \\ areny@changan.com.cn, byanggl@ changan.com.cn
}

\begin{abstract}
Keywords: Plug-in Hybrid Electric Vehicle; Extreme Learning Machine; driving cycle recognition; optimization energy management strategies; energy consumption economy
\end{abstract}

\begin{abstract}
In order to make the plug-in hybrid electric vehicle obtain optimal energy consumption economy and adapt to more complex working environment, the optimization energy management strategies based on driving cycle recognition were made. First, six kinds of cycle as standard working were selected to represent urban congestion, city suburban and highway, and the characteristic parameters of block segmentation were calculated by use of composite uniform method. Second, the extreme learning machine was applied to train and identity working conditions. Third, the optimum algorithm was applied to calculate the energy distribution rules of six standard cycles, which was stored control parameter library in order to call. On the MATLAB/SIMULINK platform, the optimization mode was built and the energy management strategy of conditions recognition and conditions without recognition were simulated. Simulation results indicate that the energy consumption economy of control strategy based on driving cycle recognition have improved $13.8 \%, 16.4 \%, 14.8 \%, 11.1 \%$, when the initial value of SOC is $0.95,0.75,0.55$ and 0.35 .
\end{abstract}

\section{Introduction}

Plug-in hybrid electric vehicles (PHEV) can take advantage of regenerative braking and a reduction in engine size to operate more efficiently, which can achieve a much better fuel consumption cost. They get attention deeply by different countries, car enterprise and scientific research structure.

Energy management strategy has important effect for vehicle consumption economy. Currently, the energy management strategy is composed of rule-based control strategy, instantaneous optimization control strategy and global optimization control strategy. Rule-based control strategy distributes torque according to engineer experience, which has simple characteristic. But, it cannot adapt different driving cycle preferably [1], [2]. Instantaneous optimization control strategy distributes control variable dynamic, which cannot obtain best energy consumption economy [3], [4]. Global optimization control strategy can fulfill best distribution rules in driving cycle based on the optimization theory. It needs know the particular driving cycle and more time to calculation [5], [6], and [7].

In this paper, the optimization energy management strategy based on driving cycle recognition is built, in order to make the PHEV obtain optimal energy consumption economy and adapt to more complex working environment. Driving cycle recognition makes use of extreme learning machine (ELM) fulfill precision request. The power distribution MAP of engine and motor is obtained by the minimum principle. Then the simulation results are analyzed for checking vehicle economic cost based on MATLAB -SIMULINK platform.

The paper is organized as follows. In the next section, we propose the structure of PHEV that we research in this paper, and some parameters are given. In Section 2, the optimization energy management strategy based on the minimum principle is built. Section 3 presents the establishment of energy management strategy based on driving cycle recognition and simulation analysis based on MATLAB -SIMULINK platform. Finally, we conclude our paper in section 4. 


\section{PHEV Power-train}

The PHEV power-train system is composed of engine, Integrated Starter/Generator (ISG), power battery, continuously variable transmission (CVT), high-voltage electric oil pump, $\mathrm{C} 1$ clutch and 12-voltage battery. The systematic architecture of PHEV is shown in Fig.1. Parameter values and specifications for the PHEV model are provided in Table 1.

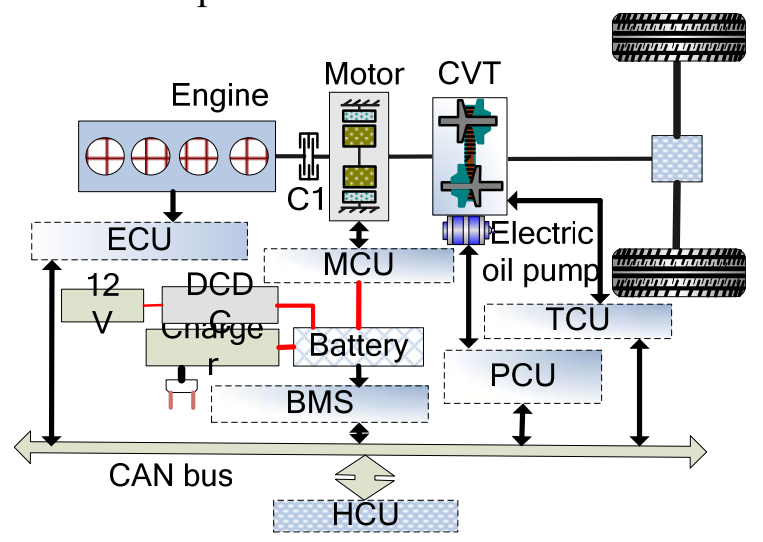

Fig. 1 The systematic architecture of PHEV

HCU (Hybrid Control Unit) can monitor the operating state and accomplish torque, speed control of engine and motor, depend upon communicating with ECU (Engine Control Unit), MCU (Motor Control Unit), BMS (Battery Management System), and TCU (Transmission Control Unit). HCU also can control $\mathrm{C} 1$ clutch coalesce or separate to realize the switch process of vehicle working mode and starting engine.

Table 1 The power-train parameters of PHEV

\begin{tabular}{ccc}
\hline Component & Characteristic & Data/Values \\
\hline \multirow{3}{*}{ Vehicle } & Mass & $1450 \mathrm{~kg}$ \\
& Frontal area & $2.28 \mathrm{~m}^{2}$ \\
& Aerodynamic drag coefficient & 0.357 \\
& Wheel radius & $0.289 \mathrm{~m}$ \\
& Rolling resistance coefficient & 0.0083 \\
Engine & Maximum power & $85 \mathrm{~kW}$ \\
& Maximum torque & $150 \mathrm{Nm}$ \\
& Maximum speed & $6000 \mathrm{rpm}$ \\
Motor & Rated power & $25 \mathrm{~kW}$ \\
& Rated torque & $\geq 100 \mathrm{Nm}$ \\
& Maximum speed & $6300 \mathrm{rpm}$ \\
Battery & Energy storage & $\geq 12.4 \mathrm{~kW} \cdot \mathrm{h}$ \\
& Rated voltage & $345 \mathrm{~V}$ \\
\hline
\end{tabular}

\section{Optimization energy management strategy based on driving cycle recognition}

The structure of control ideal about energy management strategy based on driving cycle recognition is shown in Fig.2.

It can be seen that this strategy can compare the characteristic parameters of steer data and standard driving cycle. The driving cycle style is recognized by ELM. Then the energy management strategy can extract control parameters from data-base, which can distribute the torque engine and motor sensible. 


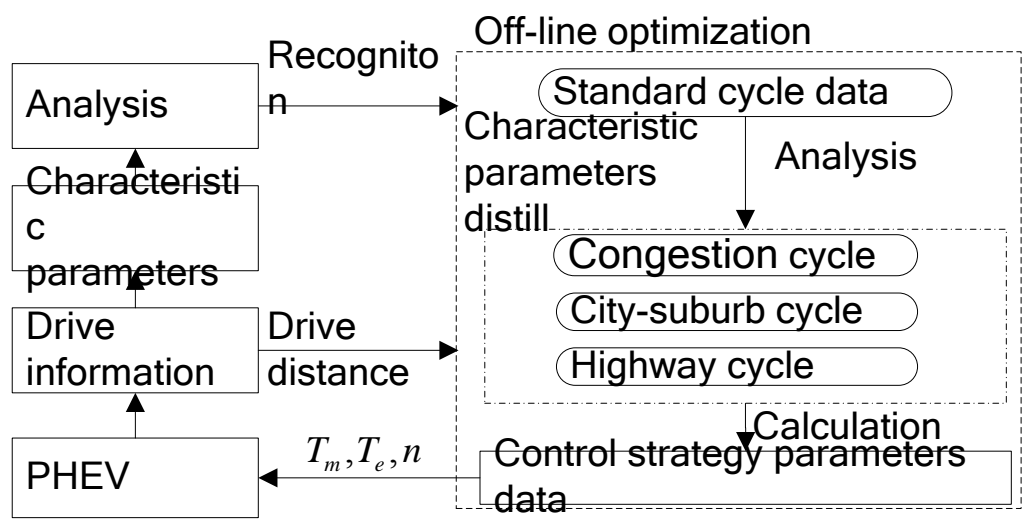

Fig.2 The optimal control thinking diagram

\subsection{Driving cycle recognition based on ELM}

\subsubsection{Characteristic parameters analysis of driving cycle}

Standard driving cycle comprises congestion cycle, city-suburb cycle, highway cycle. The different driving cycle including NYCC, New York Bus, ECE_EUDC_LOW, UDDS, HWFET, US06zzz_HWY take as the analysis stylebook.

To identify the driving cycle, the ten important characteristic parameters are extracted from the velocity during the time interval. These ten important characteristic parameters include the average velocity, the maximum velocity, the maximum acceleration, the average acceleration, the maximum deceleration, the average deceleration, idle time proportion, acceleration time proportion, deceleration time proportion and constant velocity time proportion.

\subsubsection{Extreme learning machine}

The ELM can produce connection weights between input layer and hidden layer randomly. It can also give birth to hidden neuron threshold randomly. It need set the number of hidden neuron in the process of training, which can obtain optimum solution. The realization of simulation test of main step is expressed as follow.

(1) It generates training muster form standard driving cycle. (2) It calculates the values of ten important characteristic parameters. (3It generates the number of hidden neuron to train by using ELM-train function. (4)It can be simulated by making use of ELM-predict function. (5)It calculates the error between prediction value and actual value. Then it can appraise the recognition performance.

\subsubsection{Recognition analysis}

The synthesis test driving cycle is constructed by different type cycle, which includes MANHATTAN, SC03, UDDS, 1015, WVUCITY and HWFET. There are four new driving cycle swing in with synthesis driving cycle for justice and trustiness. The velocity curve of synthesis test driving cycle is shown in Fig.3.
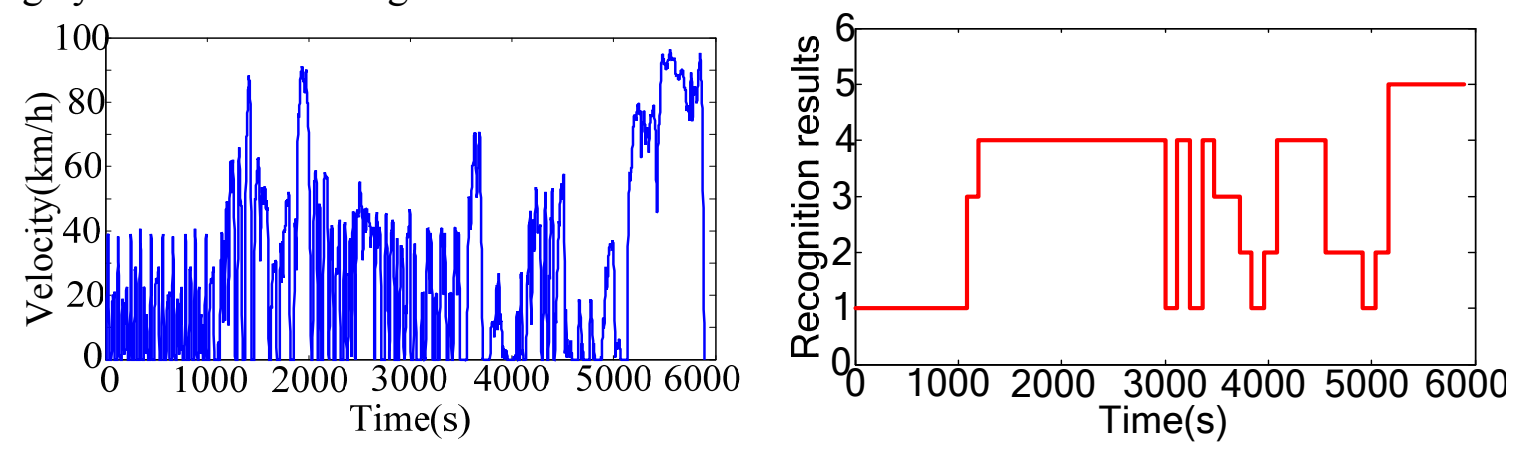

Fig.3 the comprehensive test condition Fig.4 the identify results of comprehensive test condition

The recognition result of synthesis test driving cycle is shown in Fig.4. It can be seen that the ELM can recognize the type of driving cycle better from velocity curve. 


\subsection{Simulation analysis}

The simulation of the optimization energy management strategy based on the driving cycle recognition for the comprehensive test driving cycle is conducted on MATLAB-SIMULINK platform. The economic performance comparative of the optimization energy management strategy based on the driving cycle recognition and the optimization energy management strategy without recognition is shown in Fig5-8.

The changing curve of battery SOC is demonstrated in Fig.5. It can be seen that the SOC value continuously decreases as the driving distance increasing, under the recognition strategy, in order to make full use of electricity energy. The SOC value decreases more quickly in the without recognition strategy, compare to recognition strategy. When the SOC value reaches its target value in specific distance, the vehicle operating mode is CS (Charging of Sustaining).

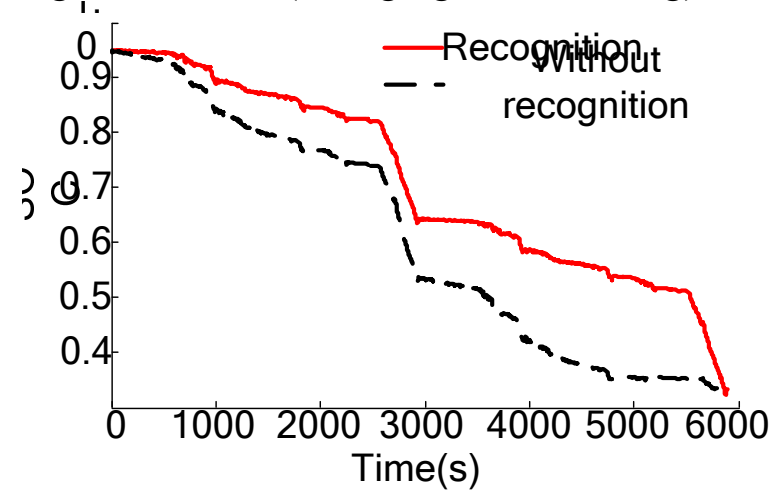

Fig.5 The changing curve of SOC

From the Fig.6 and Fig.7, we can draw this conclusion that the engine power of recognition is bigger than without recognition in different driving cycle phase $(0 \sim 1000$ s and $2000 \sim 3000 \mathrm{~s})$. As shown in these figures, the recognition strategy operates the engine at fairly high efficiency area than without recognition strategy. It also proves that the optimization energy management strategy based on the driving cycle recognition can distribute engine and motor torque more sensible.
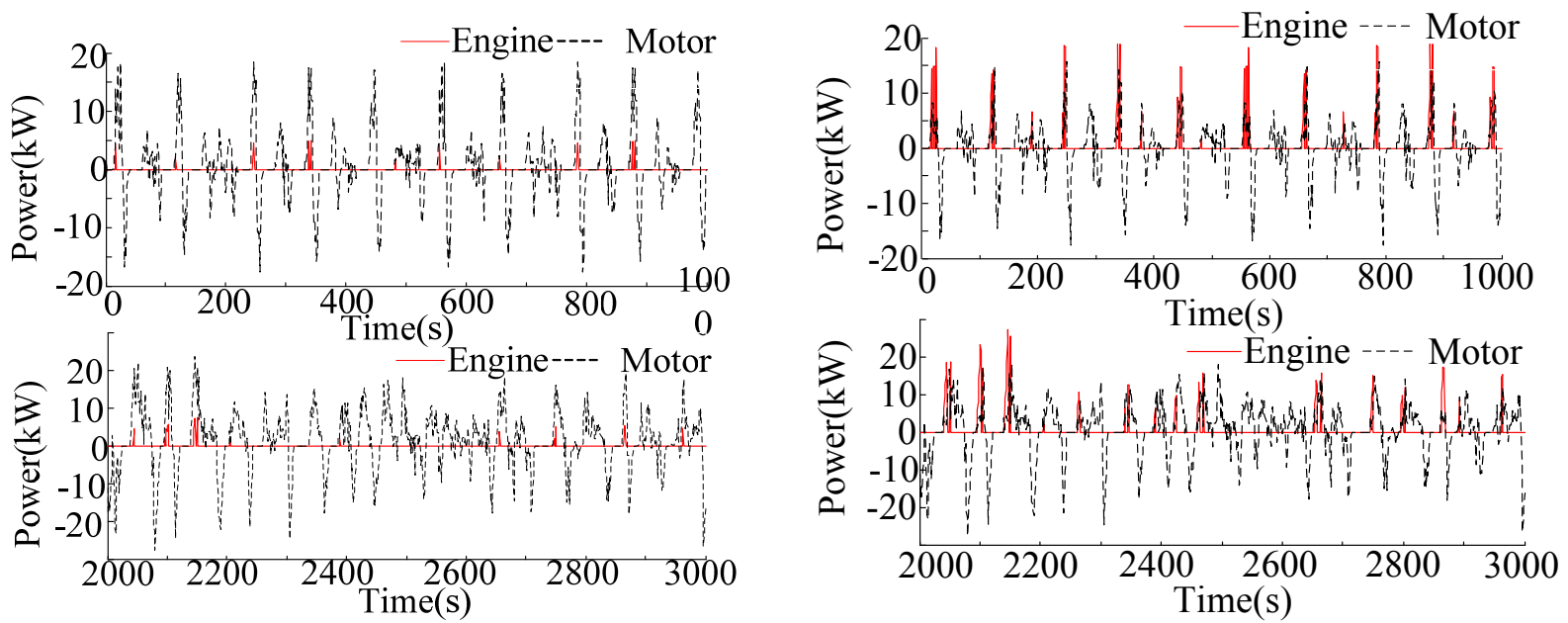

Fig.6 the power distribution of without recognition

Fig.7 the power distribution of recognition

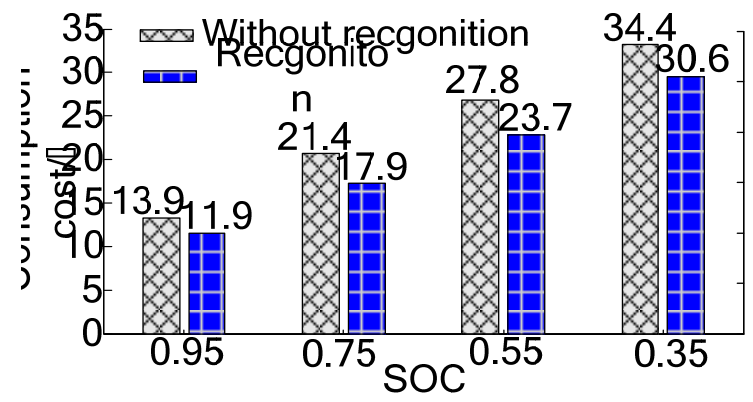

Fig. 8 the energy consumption economy 
The analysis summarized by Fig. 8 contrast the vehicle energy consumption cost of the optimization energy management strategy based on the driving cycle recognition and the optimization energy management strategy without recognition under different initial battery SOC value. From the test results, 11.1 percent to 16.4 percent of vehicle energy consumption cost could be saved.

\section{Conclusions}

In the paper, the optimization energy management strategy based on the driving cycle recognition is proposed, and the strategy overcomes the disadvantage that the optimization energy management strategy based on the minimum principle cannot obtain optimal solutions in different driving cycle. The simulation results demonstrate that can make full use of electricity energy in different initial battery SOC and travel distance, which improves engine efficiency and reduces total vehicle energy consumption cost.

\section{Acknowledgements}

The research work was supported by National Science and Technology Support Program of China under Grant No. 2013BAG12B00.

\section{References}

[1] Luo Guo-peng, Luo Yu-gong, Li Ke-qiang. Control strategy for Plug-In hybrid electric bus based on optimal electric energy use [J]. Automotive Engineering, 2012, 34(6):475-478.

[2] Zhou Neng-hui, Zhao Chun-ming, Xin Ming-hua,et al. A research on the vehicle control strategy of a plug-in hybrid electric car [J]. Automotive Engineering, 2013, 35(2):99-104.

[3] Cui Na-xin, Bu Gang, Wu Jian, et al. Real-Time optimiztion of energy management stragegy for plug-in parallel hybrid electric vehicles[J]. Transactions of China Electro technical Society, 2011,26 (11):155-160.

[4] BO GENG, JAMES K.MILLS, DONG SUN. Energy management control of microturbine-powered plug-In hybrid electric vehicles using the telemetry equivalent consumption minimization strategy [J]. IEEE Transactions on Vehicular Technology, 2011, 60(9):4238-4248

[5] Zhang Bo, Zheng He-yue, Wang cheng. Plug-in hybrid electric vehicle energy management strategy [J].Journal of Mechanical Engineering, 2011. 47(6):113-119.

[6] MOJTABA SHAMS-ZAHRAEI, ABBAS Z.KOUZANI, STEFFEN KUTTER, et al. Integrated thermal and energy management of plug-in hybrid electric vehicles [J]. Journal of Power Sources, 2012, 216: 237-248

[7] Moura S, Fathy H, Callaway D, et al. A stochastic optimal control approach for power management in plug-In hybrid electric vehicles [J], IEEE Transaction on Control Systems Technology, 2011, 19(3):545-555.

[8] Wu J, Zhang C-H, Cui N-X. Fuzzy energy management strategy for a hybrid electric vehicle based on driving cycle recognition [J]. International Journal of Automotive Technology, 2012, 13(7): 1159-1167. 